\title{
The science-media interaction in biomedical research in the Netherlands. Opinions of scientists and journalists on the science-media relationship
}

\section{Anne M. Dijkstra, Maaike M. Roefs and Constance H.C. Drossaert}

\begin{abstract}
Scientists' participation in science communication and public engagement activities is considered important and a duty. However, in particular, the science-media relationship has not been studied frequently. In this paper, we present findings from interviews with both scientists and journalists which were guided by the Theory of Planned Behavior. Results show that different behavioural, normative and control beliefs underlie scientists' and journalists' participation in science-media interactions. Both groups are positive about science-media interactions, but scientists perceive various disadvantages in this relationship while journalists perceive mainly practical barriers. Enhancing mutual understanding and further research is suggested.
\end{abstract}

Keywords

Science-media interaction; Theory of planned behaviour; Science journalism

Context

Scientists' participation in science communication and public engagement activities is considered important for a number of reasons. Poliakoff and Webb [2007] described various reasons for science communication such as the key role science plays in a number of issues facing global society and the financing of science through public funds. Therefore, scientists are obliged to share their findings. Science communication might also change perceptions about scientists and their activities, they argue, and this may lead to a more supportive public. Moreover, science communication can be enjoyable for those who take part and may enrich peoples' lives [Poliakoff and Webb, 2007; Felt and Fochler, 2012]. In addition, Bauer, Allum and Miller [2007] state that a public profile and favourable images are important to sustain public goodwill that may translate into more citations and into funding for future research, which is not only important for the scientists themselves, but also for their organizations or research institutions. More recently, according to Felt and Fochler [2012] the idea that scientists should communicate with a broader audience has become almost self-evident, and aligns with the call in Europe for more responsible research and innovation.

However, although science communication — and the related science-media interaction - is important for a number of reasons and is often considered a 
scientists' duty [see, for example, Peters et al., 2008a; Tsfati, Cohen and Gunther, 2011], and scientists are often willing to contribute [Nielsen, Kjaer and Dahlgaard, 2007], this particular science-media interaction has not often been studied. Most recent studies focus more broadly on the involvement of scientists and their institutions in science communication and engagement activities in general [Felt and Fochler, 2012; Neresini and Bucchi, 2011]. Much less research focuses on the specific science-media interaction and includes perspectives of journalists. In this paper, we aim to add to the existing knowledge of the science-media interaction by considering both perspectives. First, we discuss current literature, and, then we present and discuss results from qualitative interviews with both scientists and journalists.

\section{Scientists' perspectives}

The studies that have examined scientists' engagement with science or the science-media interaction reveal mixed results with regard to the quantity and quality of the science-media interaction. For example, Willems [2003] characterized the science-media relationship as problematic. That is, scientists lack the different writing skills to bring their work to a wider audience or feel that popularization reduces their status among peers. However, a mail survey among biomedical researchers showed that media contact of scientists in five top R\&D countries are more frequent and smooth than previously thought [Peters et al., 2008a; Peters et al., 2008b]. This survey showed that $70 \%$ of the respondents had interacted with the media in the past three years of which $75 \%$ rated their interactions as mainly positive. Interviews with both scientists and science writers confirmed these positive interactions [Geller et al., 2005]. And in a study of the Royal Society [2006], frequent levels of interaction with, amongst others, the media were reported as $74 \%$ of the responding scientists took part in at least one science communication or public engagement activity in the past year in the UK. This is in line with findings that the motivation of scientists to participate in science-media interactions nowadays is high and participation is considered a necessity and duty, or even has become almost self-evident [Felt and Fochler, 2012; Peters et al., 2008a].

More pessimistic results have been reported as well. For example, Jensen [2005] and Bentley and Kyvik [2011] found that popular publishing by scientists themselves is extremely skewed; around $50 \%$ of all popular articles were published by only 3 to $5 \%$ of all academic staff. Furthermore, a quantitative study among British scientists by The Wellcome Trust [2000] revealed that scientists mentioned many barriers with regard to their ability to participate in science communication activities, including lack of communication skills, awareness and interest, as well as time and money constraints and lack of support. The Royal Society study [Jensen, 2005], that was a follow-up on the Wellcome Trust study, showed that lack of time was the most important barrier for scientists not to participate in science communication activities, followed by perceived risks for their academic career, peer pressure and the idea that participation does not bring in funding and is therefore not a high priority activity. Bringing in more money into the department was the top incentive in this research. However, other studies reported that time constraints and career recognition did not influence the intention to participate in science communication activities [Poliakoff and Webb, 2007; Jensen et al., 2008]. 
Scientists fulfil various roles. Early on, Nelkin [1995] concluded that scientists are often portrayed as stars and are used as sources of knowledge, often outside their own area of expertise. In addition, Albaek [2011] studied the character of the interaction between experts and journalists for the Danish context and concluded that in these interactions experts - in this case researchers - are mainly asked to comment both in roles as referees and critics to confirm the journalists' framing of the news article, and as sparring partners to help understand, interpret and explain complex policy issues. Since researchers possess knowledge that is often highly relevant to public policy issues it can be argued that researchers ought to participate in public debate. In those cases they need to step out of their role as researchers but should at the same time maintain their professional objectivity by giving expert opinions instead of personal opinions [Albaek, 2011, see also Peters, 1995].

In conclusion, mixed findings are reported for scientists' perspectives on the science-media relationship. In the next section, we discuss journalists' perspectives.

\section{Journalists' perspectives}

From the perspective of journalists, not many studies have been conducted analysing the science-media relationship neither. Waddell et al. [2005] reported that journalists had difficulties finding scientists willing and able to communicate with public audiences and would like to see more researchers involved, but their study aimed at policy making instead of science communication. Amend and Secko [2012] conducted a review study analysing science and health journalists' experiences. They focused in their meta-synthesis of experiences on the journalists' behaviour and their perspective of roles and concluded that the science-media relationship is a fragile one. They advised, amongst others, to further investigate journalists' sourcing practices. Allgaier [2011] investigated these journalistic practices of selecting sources in the single case of creationism controversy in the UK press. Journalists with various backgrounds covered this case. Interviews showed that selecting sources is influenced by, amongst others, personal acquaintance with correspondents, trustful relationships between sources and journalists, reliability of sources, experiences with sources, and time constraints. Finally, in Uganda, Kaye et al. [2011] investigated the attitudes and perceived barriers towards the science-media interaction of both science journalists and health scientists. They concluded that both groups are supportive of a dialogue about communicating health science. However, barriers are inadequate or inappropriate skills of scientists, negative attitudes of 'other' scientists and lack of supportive environment by employers and peers.

\section{Theory based studies}

As far as we know, only a couple of studies investigated journalists' or scientists' opinions using a theoretical framework [e.g., Poliakoff and Webb, 2007; Felt and Fochler, 2012; Tsfati, Cohen and Gunther, 2011]. Felt and Fochler [2012] analysed individual perceptions of scientists on medial representations of science based on the concept of 'epistemic living spaces', which are described as the researchers' individual or collective perceptions and narrative re-constructions of both what researchers know and how they act in social contexts in science and beyond. They specifically focused on scientists' individual perspectives and how they influence 
the research landscape and found that the process of medialization influences the way researchers make promises about the future societal relevance of their research; researchers increasingly use the media as a resource for making the meaning of research visible and understandable and, furthermore, this medialization process influences how researchers perceive and act with regard to time dimensions related to their research.

Tsfati, Cohen and Gunther [2011] based their study on the theoretical framework of the Influence of Presumed Media Influence. This theory states that 'people's perceptions of the effects of mass media shape their reactions to media and interactions with media in important and interesting ways' (p. 145). They reported that scientists' beliefs about the influence of media increased their motivation and efforts to obtain media coverage, which was related to the number of actual appearances.

Poliakoff and Webb [2007] used and augmented in their study the Theory of Planned Behavior (TPB) [Ajzen, 1991]. In the TPB the intention to engage in certain behaviour is predicted by three factors: attitude, subjective norm (i.e., social norm) and perceived control. These factors are the result of respectively behavioural, normative and control beliefs. In turn, intention is a predictor for actual performance of behaviour. In a survey questionnaire these beliefs were investigated among 169 scientists from the UK [Poliakoff and Webb, 2007]. Results revealed that attitude (whether participation was regarded as positive), descriptive norms (whether scientists believe their colleagues participate), and perceived behavioural control (beliefs whether participation was under their control), as well as past behaviour, were all independent factors in predicting the scientists' participation in science communication activities. Other factors, such as money and time constraints, fear, possible career benefits and subjective norm did not significantly influence the intention to engage in science communication activities. However, as most studies discussed in our literature review, these studies also did not include interests of journalists who, in practice, make the science-media interaction happen.

Therefore, it is interesting - and can add to our understanding of the science-media relationship - to explore both perspectives in the science-media relationship and apply the concepts of the Theory of Planned Behavior in a qualitative approach, such as Ajzen [2011a] recommends in his later work [see also Sutton et al., 2003]. The Theory of Planned Behavior is a widely used theory which is broadly applicable and has proven to be able to add to researchers' understanding of behaviour, as is the case in the science-media relationship. Following Ajzens' argumentation that salient beliefs should always be explored qualitatively prior to starting quantitative measurements and analyses with regard to a topic, in our study we aim to qualitatively elicit salient behavioural, normative and control beliefs for the science-media interaction [Ajzen, 2011a; Ajzen, 2011b]. We, therefore, identify opinions and attitudes of both journalists and scientists towards this science-media interaction based on the three main components of the Theory of Planned Behavior (see Figure 1). Results can inform quantitative studies into the science-media interaction. As far as we know, this has not been done before for the science-media interaction. 


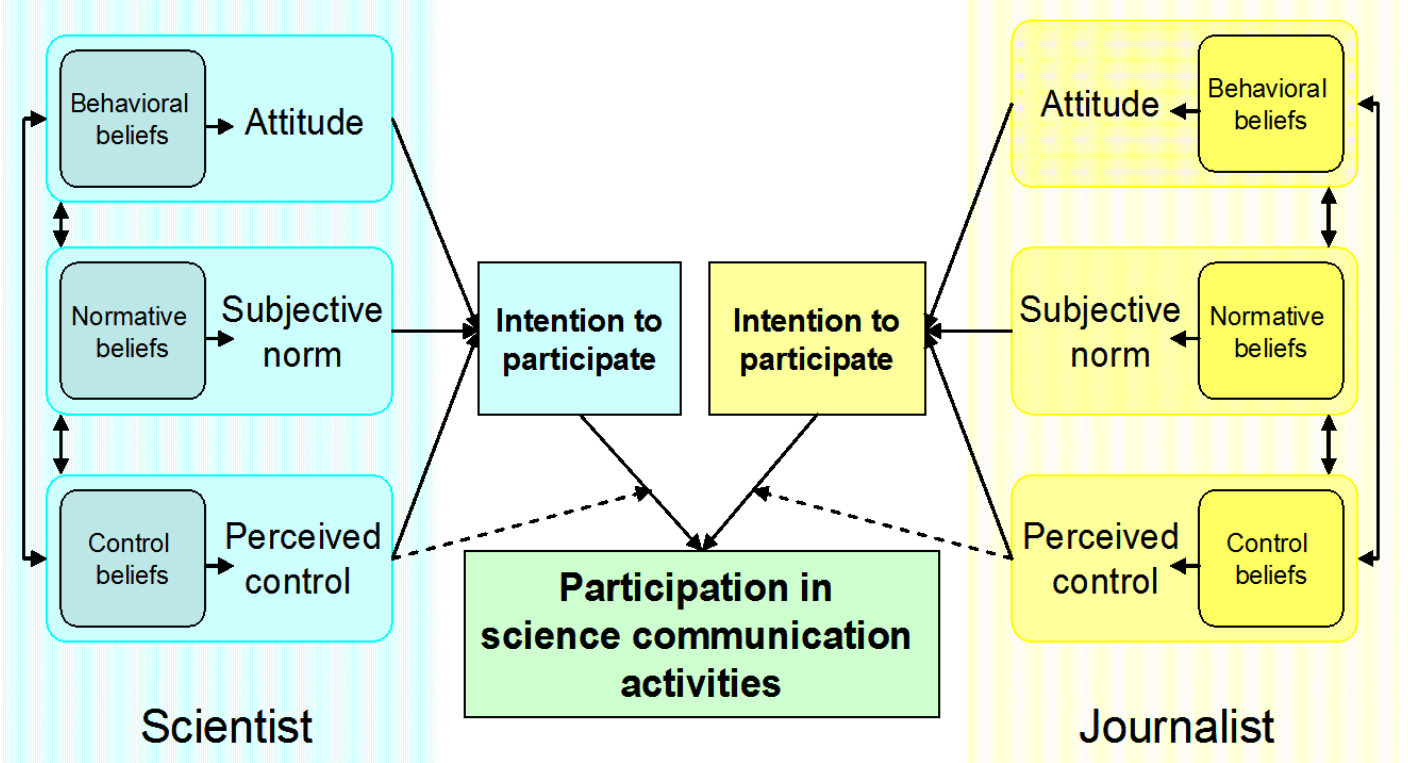

Figure 1. Schematic overview of application of the theory of planned behavior regarding participation in science-media interactions (adapted from Ajzen, 1991). Attitude, subjective norm and perceived behavioural control are the result of behavioural, normative and control beliefs, and predict intention to participate in science-media interactions, for both scientists and journalists. This will in turn predict actual participation in science-media interactions. The dotted lines represent behavioural control, which might influence the behavior directly.

To elicit the wide range of beliefs regarding the science-media interaction, semi-structured interviews were conducted with 21 scientists and 14 science journalists. All participants were asked if they were indeed involved in biomedical research or science journalism related to biomedical research and if they were willing and able to participate. Included scientists were all involved in (bio)medical research within an academic medical centre in the Netherlands. Scientists with different levels of scientific experience were invited to participate in the study, ensuring sufficient variation. Previous participation in science-media interactions was taken into account: scientists who were known to be either very active $(n=5)$ or not active at all $(n=3)$ in science-media interactions were included in this study. Other scientists $(n=13)$ were randomly selected from a list of all researchers working in the hospital. Science journalists were contacted via both existing contacts of the hospital's communication department $(n=6)$ and via the national society of science journalists $(n=8)$. All journalists had published about Dutch biomedical research before. To obtain variation within the sample science journalists with different levels of experience in the (bio)medical field who have been writing for different (types of) media were selected. All but one considered themselves indeed a science journalist. This journalist considered his work no different than the work of other journalists.

A semi-structured interview guide was composed according to the guidelines defined by Ajzen [2011b]. In addition, demographic data were collected and respondents were asked to reflect upon their previous experiences with science communication activities and the science-media interaction. Comparable guides were used for the interviews with scientists and science journalists. Although the themes were defined, the interview scheme allowed for probing, flexibility and deeper examination of issues arising during the interview. Gender differences were 
not specifically addressed. The interviews lasted between 30 to 45 minutes and were audiotaped with the respondents' permission and transcribed verbatim.

Computer-assisted qualitative data analysis was performed using Atlas.ti 6.2 software. First, all members of the research team read all the transcripts to familiarize with the data. Relevant fragments were selected by one coder (MR), and thematically arranged according to the components (attitude, subjective norm and perceived control) and related beliefs (behaviour, normative and control) in line with the Theory of Planned Behavior. Subsequently, data was further categorized into themes and sub themes using an inductive process, meaning that patterns, themes and categories arise from the data. This analysis was done by all three coders independently. The coders met on multiple occasions to discuss their findings, and resolve differences until consensus about the final themes and subthemes was reached.

In this section, first, an overview of respondents' characteristics is given and respondents' experience regarding their participation in science-media interactions is described. Thereupon, respondents' beliefs with regard to the three components within the Theory of Planned Behaviour - attitude, subjective norm, and perceived control - are presented and compared. In addition, the role of science communication mediators was explicitly discussed.

\section{Respondents' characteristics and their experiences with science-media interactions}

The study sample consists of 21 scientists and 14 journalists. The majority of both groups had more than five years of scientific experience or professional experience in journalism (See Table 1). The journalists' backgrounds varied. Most of them had a background in (bio)medical sciences, life sciences, biology or sciences, while two journalists had a background in history and one had a background both in French and science. Journalists were working both as free lancers and as employees for various types of organisations such as popular (biomedical) magazines and newspapers. All of them published about biomedical sciences and related topics, often because they had a specific interest in this topic, while a few journalists wrote stories about a broader range of science topics and did not specifically address biomedical topics only.

Furthermore, Table 1 shows that three-quarters of the scientists had experience with science-media interactions, but only a minority of them on a regular basis. When asked how scientists and journalists came into contact with each other, most scientists indicated that the journalists usually contacted them directly by phone or e-mail, or sometimes they get in touch with a science journalist via the hospital's communication department. A few scientists indicated they contacted journalists themselves when they thought they had an interesting story. These scientists were experienced in science communication activities (in general) and most had science journalists within their professional networks. Some others thought it was the role of the organization's communication specialist to get in touch with the journalist when they want to bring news. Participation in written press was the most common for the respondents, although some gave television or radio interviews and discussed science with a lay public at events (such as, science cafés). 
Table 1. Characteristics of the research sample $(n=35)$.

\begin{tabular}{lll}
\hline & Scientists $(\mathrm{n}=21)$ & Journalists $(\mathrm{n}=14)$ \\
\hline Sex & $n$ & $n$ \\
Male & $13(62 \%)$ & $7(50 \%)$ \\
Female & $8(38 \%)$ & $7(50 \%)$ \\
\hline Years of experience & & \\
$<5$ & $4(19 \%)$ & $2(14 \%)$ \\
$5-10$ & $1(5 \%)$ & $5(36 \%)$ \\
$11-20$ & $4(19 \%)$ & $5(36 \%)$ \\
$21-30$ & $8(38 \%)$ & $1(7 \%)$ \\
$>30$ & $4(19 \%)$ & $1(7 \%)$ \\
\hline
\end{tabular}

Frequency of participation in science communication

Never $\quad 5(24 \%)$

$<1 \times$ per year $\quad 6(28 \%)$

$>1 \times$ per year $\quad 6(28 \%)$

$>1 \times$ per month $\quad 2(10 \%)$

$>1 \times$ week $2(10 \%)$

*Scientific experience of scientists, and professional experience of journalists was defined as the number of years involved in research for scientists and number of years involved in science journalism, respectively

Table 1 also shows that half of the journalists had more than ten years of experience. For more insight in their behaviour, journalists were asked what steps they usually take when they report about science. Five steps could be distinguished:

1. Deciding what to write about;

2. finding a scientist to interview;

3. contacting the scientist;

4. interviewing and

5. writing.

Journalists indicated that the topic they publish about is sometimes already defined by the publisher, but often depends on the journalists' personal interests and the newsworthiness of the subject (step 1). The definition of this 'newsworthiness' is ambiguous, but science journalists mentioned factors such as relevance for the public, previous coverage, knowledge about the subject and novelty of the news. When the topic is defined, journalists search for scientists to be interviewed (step 2). Sometimes this scientist is already selected by the publisher, or the name and contact details of the scientist are readily included in the press release. However, often science journalists themselves seek independent experts' advice and ask for a reaction on the topic. They use their personal network, or the Internet, to find a relevant expert. This expert will then be contacted (step 3) either directly or via the communication department of the institute. Some journalists take their time to thoroughly prepare the interview (step 4), by reading other news items and scientific publications on the subject. After writing (step 5) most journalists provided scientists with the opportunity to read their articles before they are published to ensure correctness. 
In relation to the attitude component and behavioural beliefs towards science communication activities, most respondents, both scientists and journalists, noted that the quality of science journalism varies and differs strongly between and within different media. Journalists criticized the journalistic process where news is copy-pasted from press releases and the information is not checked before publishing. A journalist elaborated on this:

"There is real low-quality journalism, especially when it comes to the Internet... [...] That is absolutely inferior, there is no control whatsoever, it's just copy and paste. It appears on many sites at the same time. In the main newspapers, at least, they apply some basic rules of journalism: controlling, verifying and adding extra comments" (Journalist 12:85-87)

Journalists also stressed that science journalists should always be very critical, and they all hoped to contribute to correct and high-quality science journalism.

In general, scientists expressed a positive attitude towards science-media interactions. They appreciated the effort that is being put into bringing science to the public and they believed some science journalists do their work really well. However, they also mentioned many shortcomings. Scientists believed that popular articles about science often lack nuance and are sensationalized. Moreover, they believed that articles or other products are frequently incomplete and the scientific findings are misunderstood, and therefore of low quality. In addition, the used sources are sometimes unclear or unavailable and scientists felt that coverage might be biased. One scientist expressed his doubts regarding journalistic products:

"When it comes to that [journalistic products] about my own field, I think: 'What is it often wide of the mark'. And that makes you doubt all the other stuff you read; what will hold true." (Scientist 14:44)

In addition, to satisfy their own interests, scientists often mentioned that they would like to read more background information of the presented findings and the applied research methods.

More specifically asked about the advantages and disadvantages (behavioural beliefs) of participating in science communication, scientists and journalists mentioned more advantages than disadvantages. Advantages and disadvantages that were mentioned by both journalists and scientists could be divided into three main categories, those for the scientist, for the research field and for the public. See Table 2.

With regard to advantages for scientists, most respondents thought that participation in science-media interactions would make the scientists' name more well-known, which might be an advantage for obtaining grants or promotion. However, some respondents of both groups thought it would not have an effect, and some scientists mentioned that participation should not be rewarded. These scientists believed that researchers should be evaluated by their scientific work only. Other advantages that both scientists and journalists came up with, include 
Table 2. Beliefs of scientists and journalist of advantages and disadvantages related to participation in science-media interactions.

\begin{tabular}{|c|c|}
\hline Advantages & isadvantages \\
\hline \multicolumn{2}{|c|}{ For scientists } \\
\hline - Improving reputation & \multirow{6}{*}{$\begin{array}{l}\text { - Loss of reputation } \\
\text { - Communicating strategic information }\end{array}$} \\
\hline - Increasing chances for grants & \\
\hline - Possible to influence policy making & \\
\hline - Enjoying dissemination & \\
\hline - Acknowledgement of their work & \\
\hline - Enhancing critical reflection of their & \\
\hline \multicolumn{2}{|c|}{ For the research field } \\
\hline - Getting attention for research & - Decreasing support \\
\hline - Informing colleagues & \\
\hline - Increasing financial support & \\
\hline \multicolumn{2}{|c|}{ For the public } \\
\hline - Sharing knowledge & - Providing incorrect information \\
\hline - Enabling behavioural change & - Inducing anxiety \\
\hline - More understanding of the scientific & - Inducing false hope \\
\hline process & - Increasing uncertainty about what to \\
\hline $\begin{array}{l}\text { - More understanding of diseases and } \\
\text { patients }\end{array}$ & believe \\
\hline - A role in reducing anxiety for sci- & \\
\hline $\begin{array}{l}\text { entific outcomes } \\
\text { - Of interest for a general public they }\end{array}$ & \\
\hline enjoy information & \\
\hline
\end{tabular}

the possibility to influence policy making, enjoyment, improvement of the scientists' acknowledgement and the contribution to the critical reflection of their own work, as is illustrated by a journalist:

"It can influence your career; you will get better in your research field. It is an underestimated effect, but Einstein once said that if you can't explain it to your grandmother, you do not understand. Especially, when communicating to the lay public what you are doing, you can get a more clear view about your own field of work." (Journalist 3:111)

Advantages for the research field include enhancing attention and goodwill, informing colleagues about the research which leads to more knowledge and might also result in new ideas or collaborations that will expedite the scientific process, and increasing financial support.

Finally, sharing knowledge was considered the main advantage for the public. Both scientists and journalists think that an informed public is able to make more valid decisions regarding their own health and behaviour. An informed public will have a better understanding of the scientific process in general and show more respect for patients and its diseases. In addition, when the public is well-informed, this might also reduce anxiety for certain new techniques or products and taboos can be overcome. Enjoyment of the public is an important advantage as well, which might also result in the recruitment of students and future scientists. In general, 
journalists mentioned the public's enjoyment more often, whereas the scientists seemed to focus on advantages for the research field and themselves.

We found a remarkable difference between the behavioural beliefs regarding disadvantages of scientists and journalists. Whereas most scientists immediately answered the question "What are the disadvantages of participating in science communication?" with several negative factors with regard to the science-media interaction, journalists answered this question in a more nuanced way and considered disadvantages only to be present when this interaction goes wrong.

The most important disadvantage that scientists mentioned for scientists is loss in credibility, trust and status, which leads to reputation damage and affects one's career. Whereas some respondents from both groups believed it will destroy ones career, others thought it will be a temporary effect and can be overcome. Another disadvantage the group of scientists mentioned, is the fact that information about the research may be used by competing research groups. However, most respondents stressed the fact that this rarely happens, since, in general, research findings are communicated to the public after being published in a peer-reviewed journal.

A general disadvantage for the research field is a negative perception, which might harm financial and public support of the research. With regard to the disadvantages for the public, scientists believed sensationalism is an important hindering factor which can lead to the spreading of incorrect information and may induce anxiety and false hope among the public. Due to the uncertainty surrounding the scientific process, the discussions among scientists in the public domain and the information overload on the Internet, the public might get confused and uncertain about what and who to believe.

In sum, with reference to attitude, some scientists are reluctant to participate, mainly, because of the possible disadvantages they foresee for their own reputation. However, most of them do see the importance of science communication and are willing to participate when asked. Journalists see disadvantages when the interaction process fails. Some scientists and most journalists considered participation a scientists' duty, since their research is funded by public money.

\section{Subjective norm}

Secondly, to elicit normative beliefs, scientists were asked how they thought that both scientists and journalists would feel about scientistsâĂŹ participation in science communication, and, vice versa, journalists were asked these questions about journalistsâĂŹ participation. Normative beliefs appeared to be more relevant for scientists than they were for journalists. That is not unexpected, since it is the journalists' job to be involved in science-media interactions. In contrast, science-media interactions add to the scientist's normal tasks as a researcher and demand time and effort. Therefore, the answers regarding normative beliefs mainly focused on scientists' participation. See Table 3.

With regard to beliefs about colleagues, scientists stated that, particularly, colleagues play a very important, but ambiguous, role. Some scientists reported that 
Table 3. Normative beliefs of scientists and journalists about participation in science-media interactions.

\begin{tabular}{|c|c|}
\hline \multicolumn{2}{|c|}{ Beliefs about colleagues } \\
\hline $\begin{array}{l}\text { Scientists about scientists } \\
\text { - Important role for colleagues (support } \\
\text { and criticism) } \\
\text { - Both encouraged and discouraged by } \\
\text { colleagues } \\
\text { - Mixed feelings about scientists in me- } \\
\text { dia } \\
\text { - A delicate balancing act }\end{array}$ & $\begin{array}{l}\text { Journalists about journalists } \\
\text { - Network is useful, but may lead to } \\
\text { bias } \\
\text { - Convenience reasons and time pres- } \\
\text { sure influence choice for scientists }\end{array}$ \\
\hline \multicolumn{2}{|c|}{ Beliefs about each other } \\
\hline $\begin{array}{l}\text { Scientists about journalists } \\
\text { - Basic skills are required } \\
\text { - Academic degree is needed } \\
\text { - Journalists differ from each other } \\
\text { - The quality of a journalist is related to } \\
\text { the characteristics of the media } \\
\text { - Intentions are not always clear } \\
\text { - Journalists have power } \\
\text { - Journalists can be arrongant } \\
\text { - Journalists are difficult to talk to and } \\
\text { are demanding } \\
\text { - Enjoyment }\end{array}$ & $\begin{array}{l}\text { Journalists about scientists } \\
\text { - Scientists need basic skills } \\
\text { - Scientists show enthusiasm and, } \\
\text { eagerness } \\
\text { - Scientists work in specialized fields } \\
\text { - The quality of the media influences } \\
\text { decisions to participate } \\
\text { - Position science } \\
\text { - Journalists often enjoy talking to sci- } \\
\text { entists } \\
\text { - Scientists are willing to participate }\end{array}$ \\
\hline
\end{tabular}

colleagues are important in the process of the science-media interaction. They encourage and support each other, for example, by discussing the possibilities and messages or sending journalists to a colleague who may be a more suitable expert to interview. In some cases dissemination is supposed to be part of the project and scientists are encouraged to play an active role in this process.

At the same time, the criticism of colleagues is an important reason not to participate in science-media interactions. A scientist said:

\begin{abstract}
"When I started my training here as a neurologist; there was the chief of the department, he was a very famous neurologist, one with a very old-fashioned opinion on interactions with the media. He used to say: 'A doctor is in the news only twice: when he is born and when he dies. Everything in between you should avoid.' So he was really against it, like, you shouldn't communicate in the media. [...] There is always a small group of people who does not like it and is critical." (Scientist 5:38)
\end{abstract}

Almost all scientists mentioned that they have mixed feelings about other scientists who appear in the media frequently. On the one hand, some admire these scientists, because they are both experts in their field and good communicators. They therefore think it is logical that they are regularly asked to comment. On the other hand, some scientists felt that those colleagues are idle and presumptuous and overplay their role as an expert. It can be too much of a good thing. The balance between these contrasting feelings appeared to be extremely delicate and seemed to 
depend on personal values and the message of the interviewee as is illustrated by the reaction of a scientist:

“... That I sometimes see scientists on TV of whom I think: 'I couldn't be able to do that in such way. Staying calm and explaining comprehensibly with all the cameras and the spotlights. Very well done'. So, as long as it is being done in a sincere way, and I feel there is a message brought across which I think it is an important one, then I think that that is fine. That there is someone who really finds pleasure in being on the news that often, well, that's how life is, that doesn't bother me." (Scientist 16:89)

Besides encouragement by their colleagues, scientists mentioned that superiors, sponsors and patients also encourage their participation, although one respondent felt discouraged by the association of medical specialists he is part of.

Only a few journalists seemed to be aware of the existing criticism between colleague-scientists and their role within this process. Journalists argued that it is very useful and valuable to know scientists who are good communicators and who are always willing to participate, and, therefore, these scientists are frequently asked to participate. Some journalists believed this does sometimes give a biased view and they felt that other experts should be invited to participate as well. However, reasons of convenience, or time pressure, prevent journalists from asking other scientists to comment.

Both respondent groups were asked what their beliefs about each other were. Both groups agree on the basic requirements for good science journalism. Both scientists and journalists thought that science journalism is a specialized field within journalism which requires additional skills and a scientific background. However, respondent groups did not agree on the specific background. Most scientists believed science journalists should have an academic degree within the field they are writing about, whereas journalists believed a general scientific background with enthusiasm and the eagerness to learn about other topics should be enough. Both groups believed scientists should have some insight in how the media works and, most importantly, they should be able to translate the scientific findings to a comprehensible story for the lay public.

More in particular, when scientists were asked about journalists, almost all scientists stressed that they experience large differences between journalists. The quality of the journalist is perceived to correspond with the quality of the medium they are working for. Scientists felt that journalists should be both critical and scrupulous, and they stated that some of them definitely are critical; however, the journalists' intention is not always clear to the scientist. Scientists believed that some journalists only want to 'score' with sensational stories for which they use scientists. In addition, several scientists thought that some journalists are not aware of their power and the possible impact their journalistic products may have on the public, the research field and scientists. Some scientists considered journalists to be arrogant since journalists want to decide what research is important for the lay public and they do not listen to the scientistsâĂŹ feedback. In some cases they seem not to have prepared themselves for an interview. Some scientists believed that journalists think only part of all the performed research is interesting enough, 
while others said that journalists respect the difficulty of science and performing research and that they enjoy talking about it.

The perception of the journalists about the scientists' beliefs is fairly consistent with the current beliefs scientists have about journalists. The journalists expected scientists to acknowledge the quality of journalism which influences decisions whether to participate or not. Journalists believed scientists have different ideas about and levels of respect for science journalists. Whereas some journalists believed that scientists think science journalism is inferior to science, other journalists believed scientists show respect for them and their journalistic work. This difference in opinion is illustrated by two journalists:

"Most scientists tend to think that science is the most beautiful and most difficult on earth, and that all the other, including journalism, are lower in rank. And thus, that scientists can do everything better than others." (Journalist 5:99)

"I often notice that they [scientists] do realize that it [science journalism] is a specialized field which requires certain skills. They do notice, yes, they do." (Journalist 10:150)

Journalists enjoyed talking to scientists, since they are enthusiastic about their work and inspire. They argued that although scientists sometimes use jargon, if the scientists is enthusiastic, it will always work out well. Journalists believed most scientists are pleased and willing to participate. However, some scientists are reserved or reluctant and seem to be frightened or suspicious. Journalists considered this the result of previous negative experiences. Most journalists believed that scientists do not require specific skills to participate. As long as a scientist is willing and able to talk, the journalist will take care of the rest, as this journalist explained:

"If I work as a science journalist and I interview a scientist for a story, then I believe it is my task to make sure it works out well, not his. So if he cannot explain the topic well or is disorganized, it is my task to solve it. So, I believe he does not require specific skills." (Journalist 31:92)

In sum, scientists generally perceive encouragement from their social environment to participate in science communication, although some are critical about colleagues, when they appear in the media, and some also fear criticism from colleagues if they would appear in the media. Therefore, scientists' normative beliefs about other scientists revealed mixed feelings about their colleagues when they appear in the media. Journalists are critical of other journalists with regard to the efforts journalists take when establishing science-media interactions. Scientists expressed critical reflections about journalists but agreed with journalists that basic skills and enthusiasm are conditional for science-media interactions. In general, journalists perceive the relationship between scientists and journalists as more positive than scientists do. 
Table 4. Control beliefs of scientists and journalists in science-media interactions.

\begin{tabular}{|c|c|}
\hline \multicolumn{2}{|c|}{ Negative control beliefs about science-media interactions } \\
\hline For scientists & For journalists \\
\hline - Negative experiences & Regarding the communication with scientists \\
\hline $\begin{array}{l}\text { - Uncertainty about outcomes of } \\
\text { research } \\
\text { - Criticism of colleagues } \\
\text { - Ethical implications of research } \\
\text { - Lack of communication skills } \\
\text { - Lack of knowledge of the com- } \\
\text { munication process }\end{array}$ & $\begin{array}{l}\text { - Lack of communication skills of scient- } \\
\text { ists } \\
\text { - Finding the right person } \\
\text { - Take over the lead in the interview } \\
\text { - Dealing with the wishes of scientists re- } \\
\text { garding the journalistic article }\end{array}$ \\
\hline $\begin{array}{l}\text { - Unawareness of possibilities } \\
\text { - Irrelevance of research topic }\end{array}$ & Regarding science communication in general \\
\hline $\begin{array}{l}\text { - Insufficient support from de- } \\
\text { partment } \\
\text { - Less time for research and pa- } \\
\text { tients }\end{array}$ & $\begin{array}{l}\text { - Subject is difficult to understand } \\
\text { - Choosing the relevant and newsworthy } \\
\text { topic } \\
\text { - Lack of checking facts because of time } \\
\text { pressure } \\
\text { - Limited space available }\end{array}$ \\
\hline \multicolumn{2}{|c|}{ Positive control beliefs } \\
\hline $\begin{array}{l}\text { For scientists } \\
\text { - Media training can help } \\
\text { - Experience } \\
\text { - Support from e.g. communication } \\
\text { department (training, feedback, } \\
\quad \text { practicing an interview) } \\
\text { - Personal network } \\
\text { - Check and give feedback on results }\end{array}$ & $\begin{array}{l}\text { For journalists } \\
\text { - Access to the scientist } \\
\text { - Willingness of the scientist } \\
\text { - Number of possible topics } \\
\text { - Quality of press releases } \\
\text { - Background of the journalist } \\
\text { - The use of embargos }\end{array}$ \\
\hline
\end{tabular}

\section{Perceived control}

Thirdly, both groups were asked about their control beliefs, that is, which factors would impede or facilitate their participation in science communication activities. In addition, respondents discussed their ability to engage in science communication activities and their experienced or expected barriers. Comparing the groups showed that control beliefs experienced by journalists consisted of more practical issues than those of scientists. See Table 4.

With regard to negative control beliefs scientists mentioned several barriers that withhold them from participating in science communication activities. Some could we categorize under the other constructs of the theory of planned behaviour, attitude and social norm, which we discussed before. These include previous negative experiences with science-media interactions, which might result in anxiety and reluctance to participate. Negative experiences can refer to the science-media relationship in general or can refer to experiences with a specific medium or journalist. Uncertainty about the outcomes of their research may be a reason not to participate, or at least, to be reluctant about the tone of the message, because this might, for example, lead to false hope among the public or reputation damage of the scientist. As mentioned before, scientists fear the criticism of their colleagues, which can be a reason not to participate. In addition, a controversial topic or a topic with ethical implications can be perceived as a barrier. 
Barriers that are related to the scientists' perceived ability to engage in science-media interactions include lack of communication skills, lack of knowledge, unawareness of the possibilities, perceived irrelevance of their research, insufficient support and lack of time. Some scientists perceived a lack of communication skills and felt that they are insufficiently skilled to participate in science-media interactions. Most scientists argued that it is very important to tell about your research in clear language. As one scientist argued:

"... My tendency to speak in long sentences with difficult wording that is a kind of handicap for me." (Scientist 19:103)

Others mentioned that they are unaware of the possibilities, believe their research is not relevant or too complex, or they lack knowledge about the science-media relationship and, for example, do not know how to achieve media coverage. In addition, scientists considered their academic career more important than disseminating their research in popular media. Some scientists said there is insufficient support to engage in science-media interactions or it takes too much of their time.

Negative control beliefs of the journalists were distinguished in beliefs regarding communication with the scientists or beliefs regarding science communication in general. Beliefs regarding communication with scientists included lack of communication skills of the scientist and difficulties finding the right person to interview, leading the conversation, and handling the wishes of the scientist. Beliefs regarding science communication in general include the difficulty of the topic itself, choosing the topics to report on, time pressure and the limited space. Although these barriers may make the science-media interaction more difficult from the journalists' perspective, they do not withhold the journalists from participation.

Both groups mentioned lack of communication skills of the scientists as a barrier, and both groups think media training can help to overcome this barrier. It will help scientists in gaining awareness and experiences and teaches them to define a clear message, which will in turn be advantageous for journalists as well. A journalist elaborated on this:

\footnotetext{
"People sometimes have the idea that a journalist comes and asks exactly the right questions and then walks out, and is finished. But most times a journalist doesn't have a clue. He comes and thinks: 'Well, I hope they have an interesting story'. So, it has to come from the scientist himself. Some scientists don't know this and react too shy. It can help when a scientist has prepared his own story and knows: 'This is what I want to tell; these are my main messages, and I will see what happens'." (Journalist 12:73-75)
}

Both groups mentioned various positive control beliefs. Besides offering media training, scientists mentioned factors that facilitate participation, such as: experience with science communication, support from, for example, the communication department, having journalists within your personal network and being able to check the draft texts and provide feedback before publishing. According to scientists, the communication department is able to play a mediating role in the science-media interactions. They could filter information and facilitate 
interactions. However, some scientists expressed the opinion that this department is often not fully aware of the topics that scientists are working on. Journalists believed that they can help occasionally to find the right persons but this department can also delay processes. Furthermore, journalists believed that the accessibility and willingness of the scientist are important factors contributing to smooth science-media interactions. Other factors included the high amount and continuous supply of possible topics for publishing, the quality of press releases, and the journalists' background. Moreover, the use of embargos is thought to be advantageous, because it reduces the time pressure that journalists experience.

In sum, scientists and journalists perceived different negative and positive control beliefs with journalists focusing more on practical barriers in the communication with scientists and regarding science communication in general, while the group of scientists perceived also barriers related to their possibilities within their jobs. Both groups argued that media training of scientists will enhance science-media interactions.

Our study reveals what beliefs underlie scientists' and journalists' participation in science-media interactions. We qualitatively elicited both groups' salient behavioural, normative and control beliefs based on the Theory of Planned Behavior. Our study is one of the few that studied perspectives from both groups on the science-media relationship. In doing so, we gained in-depth qualitative understanding of both groups' beliefs. As far as we know this hasn't been done before. Our results reveal, first of all, that both groups have a generally positive attitude towards the science-media interaction. Most scientists in our study believe it is important to share knowledge with a broader audience, because everyone has the right to be informed about science, which is in line with results from previous studies [Felt and Fochler, 2012; Nielsen, Kjaer and Dahlgaard, 2007]. They therefore considered participation in science communication activities and in science-media interactions in particular, as their duty. In addition, increasing chances for obtaining grants and funding is a very important perceived benefit for scientists. The studies by the Jensen [2005] and Geller et al. [2005] confirm these as incentives as well. In addition, journalists mentioned the enjoyment of the public more often as an advantage, whereas the scientists seemed to focus on the advantages for the research field and themselves. Perceived negative effects that were mentioned, such as risks for the scientists' academic career and peer pressure were also important barriers in the research of the Jensen [2005], while Poliakoff and Webb [2007] found that fear did not significantly contribute to the scientists' intention to participate in public engagement activities. Based on our findings, we think that although scientists sense some negative effects, these will not withhold most of them to participate in science communication activities.

Secondly, regarding normative beliefs, our study showed that scientists fear criticism from their colleagues when participating in science-media interactions. Dunwoody [2008] elaborates on this criticism within the scientific community and considers it to be 'residual hostility' from the twentieth century when scientists were punished for popularizing their research, for example, by denying them access to memberships of scientific societies. The fact that some scientists in this study referred to the critical colleagues as 'old-fashioned' confirms this explanation. However, these findings contradict findings that normative beliefs, that is 
subjective norms, did not contribute significantly to intentions to participate in science-media interactions [Poliakoff and Webb, 2007], possibly because scientists' opinions were measured and that study did not focus on motivations to comply with these beliefs, or, because other factors had more influence on the intention to participate. While our study, in which we conducted explorative interviews, is suitable to unravel the overview of beliefs and characterize these, however, it is not possible to tell which beliefs will be more pressing than others.

Furthermore, our results indicate that scientists are not always aware of the expectations of the journalists which might hinder the science-media relationship. Both respondent groups held different opinions on the background that science journalists needed. Dunwoody [2008] showed that although formal science education makes a modest difference, the number of years on the job is the best predictor for the quality of journalistic work, which means that a relevant scientific background, as scientists would prefer, is less important. Our findings point also to underlying ideas from both scientists and journalists about the role of (scientific) knowledge in our contemporary society. Scientists, trained for years to base their decisions on scientific findings only, naturally, emphasize the need for scientific knowledge, while journalists not necessarily hold these beliefs because they are more aware that scientific knowledge is not the only knowledge needed in society, and thus not the only information that informs high quality articles. Therefore, it would be interesting to further investigate the role of scientific knowledge or scientific expertise in the public domain [see also Felt and Fochler, 2012; Rödder, 2012] as has been argued by Nelkin [1995] as well.

Thirdly, analysing control beliefs revealed that scientists and journalists perceive different barriers in the science-media interaction. Journalists experienced barriers merely as practical issues such as time constraints that scientists have. Almost every journalist mentioned that being critical and sceptical is an important condition for achieving the ideal high-quality journalism. While Waddell et al. [2005] reported that journalists experience problems with finding available scientists; this did not seem to hold true for the respondents in this study. Most journalists believe scientists are willing and easy to approach. For scientists, barriers relate to scientists' lack of knowledge of how science-media interactions work, previous negative experiences and criticism towards the way science is covered in the media rather than that they relate to practical issues. Dunwoody [2004] argued that this criticism is the result of the scientists' tendency to view their peers as the main audience, while journalists believe that their readers are not interested in that level of detail that scientists would discuss with peers and, therefore, bringing across one or two accurate short take-home messages is more important. In addition, she argues that coverage of science follows journalistic rather than scientific norms, which leads to different expectations of journalists and scientists. In our study, it seems that the different beliefs of both groups are related to applying these journalistic norms instead of scientific norms. Theory of Planned Behavior, which are behavioural, normative and control beliefs. We did so, because the Theory of Planned Behavior is a widely used theory which for this study allowed for broad aspects to be analysed which can inform further (quantitative) analysis which is suggested by Ajzen [2011a]. It was well possible to 
interpret our findings according to these generic components. However, other theories, such as, for example, the value-belief norm theory developed by Stern et al. [1999] who added personal values (e.g., world views) to explain behavioural norms, for, in this case specifically environmental movements could inform future studies as well and can further enhance our understanding of the science-media relationship [see also Oreg and Katz-Gerro, 2006]. In our study we did not specifically ask about world views.

The differences between scientists' and journalists' beliefs about the science-media relationship we found in this study may partly be explained by the fact that it is the journalists' job to be involved in science-media interactions, and not the scientists' core task. Scientists therefore evaluate for each activity whether this activity might be beneficial, what the consequences are and if they believe it is worth the time and effort. Most scientists do not know how a journalist decides on a topic or the interviewee. At the same time, journalists mentioned that reasons to write about a certain topic often depends on personal motives and preferences. Defining the newsworthiness of a story is therefore a non-transparent task, for both scientists and journalists. We believe that enhancing the mutual understanding between scientists and journalists is of importance for the science-media relationship. On the one hand, it will help when scientists know how the media work and how news is made and portrayed in the media. On the other hand, journalists should gain more awareness and understanding about the hesitation and reluctance that scientists' experience. Both scientists and journalists could learn more about each other's area of expertise and we would make a plea that both groups should invest time and effort in this science-media relationship. A media training, for example, could improve control beliefs of scientists which will help scientists to better fulfil their role in the science-media interactions. This will in turn also benefit journalists and the quality of their work [see also Peters, 1995; Geller et al., 2005]. However, we also think that for journalists it might be valuable to invest in understanding scientists' motivations to engage in the science-media relationship and to explain more often how they work. It might contribute to more trust in each other's expertise.

Our explorative and qualitative research gives insight in scientists' and journalists' salient beliefs about the science-media interaction. It should be noted, however, that due to limitations, scientists included in this study were all working in the (bio)medical sciences within one specific hospital and not all journalists were included randomly. Outcomes should therefore be interpreted with caution. The study provides rich information about both groups' beliefs but is explorative of nature and refers to the Dutch situation specifically. Therefore, we advise research to further enrich our understanding of the beliefs of both scientists and journalists in the science-media interaction. This research could be set up with both qualitatively and quantitatively methods and should include representative samples of both groups. Such an approach is in line with Ajzen's suggestions that salient beliefs differ for both topics and groups and that qualitatively collected findings can inform further (quantitative) studies [Ajzen, 2011a]. In addition, studies that should include a broader range of journalists also could explore differences between science journalists and journalists from other fields in more detail. In conclusion, more awareness and knowledge of beliefs and roles of both scientists and journalists will contribute to better understanding of each groups' positions which might improve the science-media relationship. Our study could be used for prospective quantitative and qualitative research that further explores this science-media relationship. 
Acknowledgments The authors would like to thank Marleen van 't Oever for her support and advice during the interviews. We gratefully acknowledge the suggestions of two anonymous reviewers.

\section{References}

Ajzen, I. (1991). 'The theory of planned behavior'. Organizational Behavior and Human Decision Processes 50 (2), pp. 179-211.

- (2011a). 'The theory of planned behaviour: Reactions and reflections'. Psychology and Health 26 (9), pp. 1113-1127.

- (2011b). ‘TPB Questionnaire Construction'. URL: http://people. umass . edu/aizen/ (visited on 4th July 2014).

Albaek, E. (2011). 'The interaction between experts and journalists in news journalism'. Journalism 12 (3), pp. 335-348.

Allgaier, J. (2011). 'Who is having a voice? Journalists' selection of sources in a creationism controversy in the UK press'. Cultural Studies of Science Education 6 (2), pp. 445-467.

Amend, E. and Secko, D. M. (2012). 'In the Face of Critique: A Metasynthesis of the Experiences of Journalists Covering Health and Science'. Science Communication 34 (2), pp. 241-282.

Bauer, M. W., Allum, N. and Miller, S. (2007). 'What can we learn from 25 years of PUS survey research? Liberating and expanding the agenda'. Public Understanding of Science 16 (1), pp. 79-95.

Bentley, P. and Kyvik, S. (2011). 'Academic staff and public communication: A survey of popular science publishing across 13 countries'. Public Understanding of Science 20 (1), pp. 48-63.

Dunwoody, S. (2004). 'How valuable is formal science training to science journalists?' Comunicação e Sociedade 6, pp. 75-87.

- (2008). 'Science journalism'. In: Handbook of Public Communication of Science and Technology. Ed. by M. Bucchi and B. Trench. London, U.K.: Routledge, pp. 15-26.

Felt, U. and Fochler, M. (2012). ‘Re-ordering Epistemic Living Spaces: On the Tacit Governance Effects of the Public Communication of Science'. In: The Sciences' Media Connection - Public Communication and its Repercussions. Ed. by S. Rödder, M. Franzen and P. Weingart. Vol. 28. Dordrecht, Netherlands: Springer, pp. 133-154.

Geller, G., Bernhardt, B. A., Gardner, M., Rodgers, J. and Holtzman, N. A. (2005). 'Scientists' and science writers' experiences reporting genetic discoveries: Toward an ethic of trust in science journalism'. Genetics in Medicine 7 (3), pp. 198-205.

Jensen, P. (2005). 'Who's helping to bring science to the people?' Nature 434 (7036), p. 956.

Jensen, P., Rouquier, J. B., Kreimer, P. and Croissant, Y. (2008). 'Scientists who engage with society perform better academically'. Science and Public Policy 35 (7), pp. 527-541.

Kaye, D. K., Bakyawa, J., Kakande, N. and Sewankambo, N. (2011). 'The media's and health scientists' perceptions of strategies and priorities for nurturing positive scientist media interaction for communicating health research in Uganda'. Journal of Media and Communication Studies 3 (3), pp. 112-117.

Nelkin, D. (1995). Selling Science. How the Press Covers Science and Technology. Revised edition. New York, U.S.A.: Freeman and company. 
Neresini, F. and Bucchi, M. (2011). 'Which indicators for the new public engagement activities? An exploratory study of European research institutions'. Public Understanding of Science 20 (1), pp. 64-79.

Nielsen, K. H., Kjaer, C. R. and Dahlgaard, J. (2007). 'Scientists and science communication: a Danish survey'. JCOM 6 (1), A01.

Oreg, S. and Katz-Gerro, T. (2006). 'Predicting proenvironmental behavior cross-nationally: Values, the theory of planned behavior, and value-belief-norm theory'. Environment and Behavior 38 (4), pp. 462-483. DOI: 10.1177/0013916505286012.

Peters, H. P. (1995). 'The interaction of journalists and scientific experts: co-operation and conflict between two professional cultures'. Media, Culture $\mathcal{E}$ Society 17, pp. 31-48.

Peters, H. P., Brossard, D., Cheveigne, S. de, Dunwoody, S., Kallfass, M., Miller, S. and Tsuchida, S. (2008a). 'Science communication - Interactions with the mass media'. Science 321 (5886), pp. 204-205.

Peters, H. P., Brossard, D., De Cheveigné, S., Dunwoody, S., Kallfass, M., Miller, S. and Tsuchida, S. (2008b). 'Science-media interface: It's time to reconsider'. Science Communication 30 (2), pp. 266-276.

Poliakoff, E. and Webb, T. L. (2007). 'What factors predict scientists' Intentions to participate in public engagement of science activities?' Science Communication 29 (2), pp. 242-263.

Rödder, S. (2012). 'The Ambivalence of Visible Scientists'. In: The Sciences' Media Connection - Public Communication and its Repercussions. Ed. by S. Rödder, M. Franzen and P. Weingart. Vol. 28. Sociology of the Sciences Yearbook. Dordrecht, Netherlands: Springer, pp. 155-178.

Royal Society (2006). Survey of factors affecting science communication by scientists and engineers. London, U.K.: Royal Society. URL: http://royalsociety.org/uploadedFiles/Royal_Society_Content/policy/ publications/2006/1111111395.pdf (visited on 4th July 2014).

Stern, P. C., Dietz, T., Abel, T., Guagnano, G. A. and Kalof, L. (1999). 'A value-belief-norm theory of support for social movements: The case of environmentalism'. Human Ecology Review 6 (2), pp. 81-97.

Sutton, S., French, D. P., Hennings, S. J., Mitchell, J., Wareham, N. J., Griffin, S., Hardeman, W. and Kinmonth, A. L. (2003). 'Eliciting salient beliefs in research on the theory of planned behaviour: The effect of question wording'. Current Psychology 22 (3), pp. 234-251.

Tsfati, Y., Cohen, J. and Gunther, A. C. (2011). 'The influence of presumed media influence on news about science and scientists'. Science Communication 33 (2), pp. 143-166. DOI: 10.1177/1075547010380385.

Waddell, C., Lomas, J., Lavis, J. N., Abelson, J., Shepherd, C. A. and Bird-Gayson, T. (2005). 'Joining the conversation: Newspaper journalists' views on working with researchers'. Healthcare Policy 1 (1), pp. 123-139.

Wellcome Trust (2000). 'The role of scientists in public debate. Summary of research findings'. URL: http://www.wellcome.ac.uk/Aboutus/Publications/Reports/Public-engagement/WTD003429.htm (visited on 4th July 2014).

Willems, J. (2003). 'Bringing down the barriers'. Nature 422 (6931), p. 470. 
Anne M. Dijkstra, Ph.D. (University of Twente) is assistant professor at the University of Twente. She studies the relationship between science, technology and society from a communication perspective. Her research focuses on science and risk communication, risk governance and public participation regarding emerging technologies such as genomics, nanotechnologies and human enhancement. In 2013 she was a visiting researcher at Newcastle University and Durham University. http://www.utwente.nl/elan/medewerkers/dijkstra/. E-mail: a.m.dijkstra@utwente.nl.

Maaike M. Roefs, MSc studied Communication Studies and Technical Medicine at the University of Twente. Currently, she is a Ph.D. student in biomedical research at the Leiden University Medical Center in The Netherlands. Her research focuses on regenerative medicine and strategies to replace insulin-producing cells in diabetes. In addition, she works as a freelance science writer. E-mail: m.m.roefs@lumc.nl .

Constance H.C. Drossaert, Ph.D. (University of Twente) is associate professor at the University of Twente. Her research focuses on patient participation and patient-empowerment and the role of new (IT) technologies herein. She teaches various courses in the domain of Health Psychology and Health communication, and is coordinator of the mastertrack Health Psychology.

http://www.utwente.nl/bms/pgt/mw/drossaert/.

E-mail: c.h.c.drossaert@utwente.nl .

\section{How to cite}

Dijkstra, A.M., Roefs, M.M. and Drossaert, C.H.C. (2015). 'The science-media interaction in biomedical research in the Netherlands. Opinions of scientists and journalists on the science-media relationship'. JCOM 14 (02), A03. 